\title{
Behavior problems among school-aged children with autism spectrum disorder: Associations with children's communication difficulties and parenting behaviors
}

\author{
Hannah Boonen ${ }^{1,2}$, Jarymke Maljaars ${ }^{1,2}$, Greet Lambrechts ${ }^{1,2}$, Inge Zink ${ }^{3}$, Karla Van Leeuwen ${ }^{1}, \&$ \\ Ilse Noens ${ }^{1,2}$ \\ ${ }^{1}$ KU Leuven, Parenting and Special Education Research Unit, ${ }^{2}$ KU Leuven, Leuven Autism Research, ${ }^{3}$ KU Leuven, Department of \\ Neurosciences, ExpORL
}

\begin{abstract}
Research has clearly demonstrated that behavior problems are common among children with ASD. These co-occurring behavior problems place children with ASD and their families at risk for a range of negative outcomes. This questionnaire study aimed to investigate whether and how age, gender, and communication difficulties at the child level and parenting behaviors at the family level are associated with externalizing and internalizing problems among children with ASD $(\mathrm{nn}=206)$ and without ASD $(\mathrm{n}=187)$ aged 6-n = 187) aged 6-12 years. Results indicated that pragmatic language difficulties of the child and negative controlling parenting behaviors both made a significant and unique contribution to externalizing behavior problems for the ASD group. In the control group, chronological age and pragmatic language difficulties were the most robust concurrent predictors of externalizing problems. With regard to internalizing problems, pragmatic language difficulties and ASD adapted parenting behaviors were significant predictors for both the ASD and control group.
\end{abstract}

Keywords: Autism spectrum disorder, externalizing behavior problems, internalizing behavior problems, communication difficulties, parenting behaviors

\section{Introduction}

Autism spectrum disorders (ASD) are characterized by persistent impairments in reciprocal social interaction and communication across multiple contexts, along with the presence of restricted, repetitive and stereotyped behaviors and interests (American Psychiatric Association, 2013). Current evidence suggests that children with ASD often exhibit high levels of co-occurring behavior problems (Bauminger, Solomon, \& Rogers, 2010; Gray, Keating, Taffe, \& Brereton, 2012; Hartley, Sikora, \& McCoy, 2008; Kanne \&

\footnotetext{
Notice: this is the author's version of a work that was accepted for publication in Research in Autism Spectrum Disorders. Changes resulting from the publishing process, such as peer review, editing, corrections, structural formatting, and other quality control mechanisms may not be reflected in this document. Changes may have been made to this work since it was submitted for publication. A definitive version was subsequently published in Research in Autism Spectrum Disorders, 8, 716-725, doi: 10.1016/j.rasd.2014.03.008.
} 
Mazurek, 2011; Mazurek \& Kanne, 2010). Both internalizing (e.g., depressed/anxious affect, somatic complaints, and withdrawal) and externalizing (e.g., aggression, hyperactivity, and property destruction) problems are frequently present in children with ASD. Bauminger, Solomon, and Rogers (2010), for example, found that children with ASD aged between 8 and 12 years showed higher levels of externalizing and internalizing behaviors measured through the Child Behavior Checklist compared to typically developing children, with $21 \%$ of the ASD group meeting the clinical criteria for externalizing behaviors and $26 \%$ for internalizing behaviors. Prevalence figures vary, depending on the population, definition, and methods used to measure behavior problems.

These co-occurring behavior problems place children with ASD and their families at risk for a range of negative outcomes. Behavior problems can interfere with the child's daily functioning, instruction, and intervention outcomes, thereby hindering improvement across various developmental domains (Kanne \& Mazurek, 2011; Matson \& Wilkins, 2007; Taylor \& Seltzer, 2011). Moreover, behavior problems among children with ASD can affect parents’ psychological well-being, possibly contributing to elevated levels of parenting stress (Estes et al., 2013; Hastings et al., 2005; Lecavalier, Leone, \& Wiltz, 2006; McStay, Dissanayake, Scheeren, Koot, \& Begeer 2013; Tomanik, Harris, \& Hawkins, 2004), depression and anxiety (Carter, Martínez-Pedranza, \& Gray, 2009; Herring et al., 2006), beyond and above the effect of the core ASD symptoms. Furthermore, research has indicated that externalizing problems are associated with poorer family functioning, particularly with increased negativity in parenting perceptions and poorer social functioning (Sikora et al., 2013). Given the significant impact of behavior problems on the functioning and well-being of children with ASD and their families, it is important to understand which factors contribute to the emergence and

\footnotetext{
Notice: this is the author's version of a work that was accepted for publication in Research in Autism Spectrum Disorders. Changes resulting from the publishing process, such as peer review, editing, corrections, structural formatting, and other quality control mechanisms may not be reflected in this document. Changes may have been made to this work since it was submitted for publication. A definitive version was subsequently published in Research in Autism Spectrum Disorders, 8, 716-725, doi: 10.1016/j.rasd.2014.03.008.
} 
maintenance of such difficulties. This knowledge can inform health care providers in the development and delivery of prevention programs and effective interventions. The present study aims to investigate whether externalizing and internalizing problems among schoolaged children with ASD are associated with children's communication difficulties and parenting behaviors.

There is a large body of empirical literature on the presence and the various functions that behavior problems or challenging behaviors can fulfill among children with ASD (Gavidia-Payne \& Hudson, 2002; Repp \& Horner, 1999). By contrast, only a small amount of studies have investigated risk factors for the development and maintenance of such difficulties. From a developmental psychopathology framework, it is recognized that there are multiple possible pathways in the development of behavior problems, and that multiple factors may contribute to these pathways. Therefore, researchers have examined the role of various risk and protective factors in predicting trajectories of behavior problems among children and adolescents from the general population. Several factors that can influence the risk for adaptive or maladaptive outcomes are identified at the child, family and contextual level (Calkins, Blandon, Williford, \& Keane, 2007). At the individual child level, for example, the temperamental dimension of negative emotionality and early deficits in selfregulatory processes have been found to predict both internalizing and externalizing behavior problems (Calkins \& Fox, 2002; Calkins et al., 2007). Moreover, early language delays have been shown to increase the risk for aggression, especially when combined with impulse control and emotion regulation difficulties (Calkins, 1994; Dionne, Tremblay, Boivin, Laplante, \& Pérusse, 2003). Gender is also identified as an important child characteristic, with boys in general being at greater risk for the development of externalizing behavior problems

\footnotetext{
Notice: this is the author's version of a work that was accepted for publication in Research in Autism Spectrum Disorders. Changes resulting from the publishing process, such as peer review, editing, corrections, structural formatting, and other quality control mechanisms may not be reflected in this document. Changes may have been made to this work since it was submitted for publication. A definitive version was subsequently published in Research in Autism Spectrum Disorders, 8 , 
(Lahey et al., 2000; Tremblay, 2000). Regarding age of the child, research has indicated that aggressive behaviors show a significant decline across childhood for most children (Tremblay, 2000). At the family level, a large amount of research has focused on the effect of different aspects of the parent-child relationship on the development and maintenance of child behavior problems. Specific parenting behaviors, such as harsh, inconsistent, or negative parental control strategies (Kawabata, Alink, Tseng, Van IJzendoorn, \& Crick, 2011; Smith, Calkins, Keane, Anastopoulos, \& Shelton, 2004), love withdrawal or guilt induction (Barber, Stolz, \& Olsen, 2005; Finkenauer, Engels, \& Baumeister, 2005), or limited positive involvement (Caron, Weiss, Harris, \& Catron, 2006; Pettit, Bates, \& Dodge, 1997) have been identified as risk factors for the development of externalizing problems in children. With regard to internalizing problems, studies have indicated that excessive parental control (Caron et al., 2006; Wood, McLeod, Sigman, Hwang, \& Chu, 2003) or love withdrawal (Barber et al., 2005) are associated with internalizing problems among children. Research has shown that parenting behaviors can serve not only as a risk factor, but also as a protective factor in the development of behavior problems. Positive parenting behaviors, such as parental involvement and support, may protect children from developing maladaptive behavior outcomes (Barber et al., 2005; Finkenauer et al., 2005; Kawabata et al., 2011). At the contextual level a range of socio-economic risk factors are identified, such as family income, maternal education and parental employment (Hartas, 2011).

In the autism field, studies investigating risk factors for the development and maintenance of behavior problems have mainly focused on individual child characteristics, such as age, gender, cognitive functioning, adaptive behaviors, receptive and expressive language, and severity of ASD symptoms. Lower cognitive and adaptive functioning and

\footnotetext{
Notice: this is the author's version of a work that was accepted for publication in Research in Autism Spectrum Disorders. Changes resulting from the publishing process, such as peer review, editing, corrections, structural formatting, and other quality control mechanisms may not be reflected in this document. Changes may have been made to this work since it was submitted for publication. A definitive version was subsequently published in Research in Autism Spectrum Disorders, 8, 
more severe ASD symptomatology have been identified as important predictors for maladaptive behavior outcomes (Dominick, Davis, Lainhart, Tager-Flusberg, \& Folstein, 2007; Hartley et al., 2008; McTiernan, Leader, Healy, \& Mannion, 2011). With regard to language ability, receptive and expressive language levels have been shown to be negatively associated with behavior problems (Dominick et al., 2007; McTiernan, et al., 2011; Park, Yelland, Taffe, \& Gray, 2012). However, Kanne and Mazurek (2011) found that level of intellectual functioning and language ability were not predictive of aggressive behaviors in children and adolescents with ASD. Park and colleagues (2012) also found no significant association between structural language skills and behavior problems. Concerning age effects, mixed findings have been reported. For example, Kanne and Mazurek (2011) highlighted agerelated changes in aggressive behaviors, with aggression being reported more often in younger children with ASD. Matson, Mahan, Hess, Fodstad, and Neal (2010), however, found no significant differences between young children (3-6 year olds), school-aged children (7-10 year olds), and young adolescents (11-14 year olds) with ASD in challenging behaviors such as physical aggression and property destruction. Discrepancies in the findings of some of these studies can be due to methodological differences, such as varying developmental levels and chronological ages, and the inclusion or exclusion of children with a co-occurring intellectual disability.

To our knowledge, only a few studies have investigated risk factors on the family level. In a study of Bauminger, Solomon and Rogers (2010) parenting stress was identified as a significant predictor for both externalizing and internalizing behavior problems among high functioning children with ASD. Osborne, McHugh, Saunders, and Reed (2008) found a negative correlation between limit setting and child behavior problems. Furthermore, limit

\footnotetext{
Notice: this is the author's version of a work that was accepted for publication in Research in Autism Spectrum Disorders. Changes resulting from the publishing process, such as peer review, editing, corrections, structural formatting, and other quality control mechanisms may not be reflected in this document. Changes may have been made to this work since it was submitted for publication. A definitive version was subsequently published in Research in Autism Spectrum Disorders, 8, 716-725, doi: 10.1016/j.rasd.2014.03.008.
} 
setting was shown to mediate the relationship between parenting stress and subsequent child behavior problems. Midouhas, Yogaratnam, Flouri, and Charman (2013) investigated whether home organization and maternal warmth and involvement could buffer the effect of family poverty on psychopathology trajectories of young children with ASD. Although they found no evidence to suggest that warmth, involvement, and home organization buffered the effect of poverty on psychopathology, their study indicated that maternal warmth was associated with fewer conduct problems and less hyperactivity, and with an annual decrease in peer and conduct problems.

According to developmental psychopathology, multiple factors can influence the risk for maladaptive behavior outcomes among children. However, regarding ASD, research investigating risk factors at both the child and family level is rather scarce. Therefore, the first objective of this study is to investigate the role of child and family factors in the prediction of behavior problems among school-aged children with ASD. At the child level, we will investigate whether and how child age, gender, and communication difficulties are associated with both externalizing and internalizing problems. Contrary to previous studies, which often used wide age and IQ ranges, the present study focusses on children aged 6 to 12 years without intellectual disability. These children often exhibit communication difficulties, especially with regard to pragmatic language. Although the association between communication difficulties and behavior problems has been documented in studies from the general population, research examining the influence of structural and pragmatic language difficulties on behavior problems among children with ASD is limited. At the family level, we aim to investigate the contribution of parenting behaviors in the prediction of children's behavior problems. Research in the general population has clearly shown that parenting

\footnotetext{
Notice: this is the author's version of a work that was accepted for publication in Research in Autism Spectrum Disorders. Changes resulting from the publishing process, such as peer review, editing, corrections, structural formatting, and other quality control mechanisms may not be reflected in this document. Changes may have been made to this work since it was submitted for publication. A definitive version was subsequently published in Research in Autism Spectrum Disorders, 8 , 
behaviors can serve both as a protective and risk factor in the development of behavior problems. In autism research, however, little attention has been paid to the role of parenting behaviors in the development of behavior problems among children with ASD.

A second objective of the present study is to examine possible moderator effects between the child and family variables. A moderator effect occurs when one predictor affects the strength and/or direction of the relation between another predictor and the outcome variable. For example; children with more communication problems could be more vulnerable for the effects of the environment (i.e., parenting behaviors). Given the complex nature of behavior problems, it is important to investigate whether moderator effects occur. This could give us insight into possible interaction effects between children's communication difficulties and parenting behaviors in predicting behavior problems among children with and without ASD.

\section{Methods}

\subsection{Participants}

The total sample included 393 Dutch children aged between 6 and 12 years. Children with ASD $(n=206)$ were compared with a control group of children without ASD diagnosis ( $n=187)$. Children with intellectual disability (IQ below 70), as reported by the parents, were excluded from the sample. For the ASD group, parents indicated on a questionnaire whether their child had received a clinical ASD diagnosis based on DSM-IV-TR criteria for Autistic Disorder, Asperger syndrome, or PDD-NOS by qualified professionals. A large part of the participating families of these children were member of the Dutch parent association for autism. The remainder (33\%) was recruited through special schools for which a formal DSM-

\footnotetext{
Notice: this is the author's version of a work that was accepted for publication in Research in Autism Spectrum Disorders. Changes resulting from the publishing process, such as peer review, editing, corrections, structural formatting, and other quality control mechanisms may not be reflected in this document. Changes may have been made to this work since it was submitted for publication. A definitive version was subsequently published in Research in Autism Spectrum Disorders, 8, 
classification by an interdisciplinary team is required. Children with suspected ASD without formal diagnosis were excluded from both the ASD and the control group. For some children in the ASD and control group an (additional) diagnosis of ADHD (ASD group: 19\%; control group: 2\%), dyslexia (ASD group: 5\%; control group: 4\%), or another DSM-IV-TR diagnosis (such as Oppositional Defiant Disorder, Obsessive Compulsive Disorder, or Developmental Coordination Disorder; ASD group: 4\%; control group: 1\%) was reported. Table 1 shows the demographic characteristics of the ASD and the control group, and relevant parent and family characteristics.

\section{[Table 1]}

The ASD and control group differed significantly on the child characteristics age and gender. For this reason, age and gender were entered as control variables in the analyses. There were no differences between the ASD and control group with regard to parent and family characteristics. More mothers $(n=358)$ than fathers $(n=35)$ completed the questionnaire concerning their parenting behavior (ASD group: $\lesssim 7 \%, q 93 \%$; control group: $\lesssim 11 \%, q$ $89 \%$ ). The level of education of both fathers and mothers was generally high. Almost half of them completed college (i.e. received a bachelor's or master's degree). The majority of the parents was in a two-parent household. A small part was divorced, widowed, separated, or single.

\footnotetext{
Notice: this is the author's version of a work that was accepted for publication in Research in Autism Spectrum Disorders. Changes resulting from the publishing process, such as peer review, editing, corrections, structural formatting, and other quality control mechanisms may not be reflected in this document. Changes may have been made to this work since it was submitted for publication. A definitive version was subsequently published in Research in Autism Spectrum Disorders, 8, 716-725, doi: 10.1016/j.rasd.2014.03.008.
} 


\subsection{Instruments}

\subsubsection{Child behavior problems}

The Strengths and Difficulties Questionnaire (SDQ; Goodman, 1997) is a brief screening questionnaire for the assessment of psychological adjustment of children. Twentyfive positive and negative attributes of behavior are questioned, for example "restless, overactive, cannot stay still for long". Parents indicate on a 3-point rating scale to what extent each attribute applies to the target child $(1=$ not true, $2=$ somewhat true, $3=$ certainly true $)$. The 25 items are assigned to five subscales: (a) emotional symptoms, (b) conduct problems, (c) hyperactivity / inattention, (d) peer relationship problems, and (e) prosocial behavior. The SDQ demonstrated acceptable reliability and validity, both as a screening instrument (Goodman, 2001) and as a dimensional measure for quantifying the degree of an individual's strengths and difficulties (Goodman \& Goodman, 2009). The psychometric properties of the parent-report version also proved satisfactory in a Dutch sample (Muris, Meesters, \& Van den Berg, 2003). In the current study the first four subscales were used, creating two composite scores for internalizing behavior problems (emotional and peer items) and externalizing behavior problems (conduct and hyperactivity items). Factor analyses supported second-order internalizing and externalizing factors. Especially in general population samples preference is given to these broadband scales instead of the five-subscale division (Goodman, Lamping, \& Ploubidis, 2010). Dutch norm scores are available for 4 to 16 year olds.

\subsubsection{Child communication difficulties}

The Children's Communication Checklist-2 (CCC-2; Bishop, 2003; Dutch translation: Geurts, 2007) was used to assess structural and pragmatic language difficulties. This 70-item

\footnotetext{
Notice: this is the author's version of a work that was accepted for publication in Research in Autism Spectrum Disorders. Changes resulting from the publishing process, such as peer review, editing, corrections, structural formatting, and other quality control mechanisms may not be reflected in this document. Changes may have been made to this work since it was submitted for publication. A definitive version was subsequently published in Research in Autism Spectrum Disorders, 8, 716-725, doi: 10.1016/j.rasd.2014.03.008.
} 
questionnaire consists of 10 subscales: (a) speech production, (b) syntax, (c) semantics, (d) coherence, (e) inappropriate initiation, (f) stereotypic language, (g) use of context, (h) nonverbal communication, (i) social relationships, and (j) interests. Parents rate the frequency of occurrence for each item on a 4-point rating scale $(0=$ less than one time a week, $1=$ minimum one time a week, but not every day, $2=$ one or two times a day, $3=$ several times (more than two) a day (or always)). For example, parents are asked how often their child gets mixed up between he/him or she/her, e.g., says "him is working" rather than "he is working" or "her has a cake" rather than "she has a cake". Several measures indicated good reliability and validity of the CCC-2 (Bishop, 2003). Reliability measures have been re-examined and proven satisfactory in a Dutch sample (Geurts, 2007). In the current study, only eight out of the ten subscales were used, creating two composite scores. The more widely used general communication composite score (subscales a to h) was not calculated, since there is considerable overlap with the pragmatic language composite score (subscales e to h). We have chosen for a distinction between a composite score measuring structural language difficulties more purely (with items assessing aspects of articulation and phonology, language structure and vocabulary; subscales a to d) and a composite score measuring pragmatic language difficulties (e.g., inappropriate initiation and non-verbal communication; subscales e to $\mathrm{h})$. The composite scores were calculated by adding up the standardized subscale scores $(M$ $=10 ; S D=3)$. Dutch norm scores are available for 4 to 15 year olds.

\subsubsection{Parenting behaviors}

The Parental Behavior Scale-ASD (PBS-A; Van Leeuwen \& Noens, 2013) is a 52item questionnaire that comprises five subscales to measure general parenting behaviors (Van Leeuwen \& Vermulst, 2004, 2010) and two subscales to measure specific parenting behaviors

\footnotetext{
Notice: this is the author's version of a work that was accepted for publication in Research in Autism Spectrum Disorders. Changes resulting from the publishing process, such as peer review, editing, corrections, structural formatting, and other quality control mechanisms may not be reflected in this document. Changes may have been made to this work since it was submitted for publication. A definitive version was subsequently published in Research in Autism Spectrum Disorders, 8, 716-725, doi: 10.1016/j.rasd.2014.03.008.
} 
relevant to children with ASD. The general subscales are: (a) positive parenting, (b) material rewarding, (c) rules, (d) discipline, and (e) harsh punishment. The two additional ASDadapted subscales are: (f) stimulating the development, and (g) adapting the environment. In this study, three composite scores were used, namely positive parenting (items from positive parenting, material rewarding, and rules), negative control (items from discipline and harsh punishment) and ASD adapted parenting (items from stimulating the development and adapting the environment). The PBS-A is a self-report measure, in which parents are given statements about concrete parenting behaviors in everyday life towards one specific child, for example "When my child has to complete a task (e.g., homework), I restrict distraction to a minimum". The frequencies of these behaviors are rated on a 5-point Likert scale $(1=$ (almost) never, $2=$ rarely, $3=$ sometimes, $4=$ often, $5=$ (almost) always). Internal reliability was acceptable to good for all subscales. Confirmatory factor analyses supported structural validity (Lambrechts, Van Leeuwen, Boonen, Maes, \& Noens, 2011).

\subsection{Procedure}

Most of the parents from the ASD group were approached through the digital news letter from the Dutch parent association for autism. Parents were asked to give permission to participate in this study. The remainder (33\%) was recruited via four special schools for children with ASD. The control group was recruited via eight regular primary schools. After informed consent was given, parents completed the paper and pencil versions of the questionnaires.

\footnotetext{
Notice: this is the author's version of a work that was accepted for publication in Research in Autism Spectrum Disorders. Changes resulting from the publishing process, such as peer review, editing, corrections, structural formatting, and other quality control mechanisms may not be reflected in this document. Changes may have been made to this work since it was submitted for publication. A definitive version was subsequently published in Research in Autism Spectrum Disorders, 8, 716-725, doi: 10.1016/j.rasd.2014.03.008.
} 


\subsection{Data Analyses}

All analyses were performed using IBM SPSS Statistics 20. Fathers and mothers were taken together as one group in the analyses, since the number of fathers was too small to consider them as a separate group. First, exploratory analyses were conducted, by calculating Pearson correlations between child age, gender, communication difficulties, and parenting behaviors and child internalizing and externalizing problems. To compare means on the SDQ subscales for the ASD versus control group, an independent samples T-test was performed. Next, four hierarchical regression analyses were conducted in order to determine predictors of externalizing and internalizing behavior problems for the ASD and control group separately. In each analysis, age and gender (boys were coded as 0 and girls as 1) of the child were entered in the first step. Communication difficulties were entered in the second step, and parenting behaviors were entered in the third step. The fourth and final step consisted of 6 two-way interaction terms between communication difficulties and parenting behaviors, represented by multiplicative products (e.g. pragmatic language difficulties $\mathrm{x}$ positive parenting), in order to examine possible moderator effects. Evidence for a moderator effect is found when there is a significant increase in the multiple $R^{2}$ after entering the interaction terms. Independent variables were checked for multicollinearity. VIF values were calculated and were all below 10 (Field, 2009). Furthermore, all correlations between the predictors were below $r=0.70$. No more than $5 \%$ of all cases had standardized residuals with an absolute value greater than 2 (Field, 2009). All other basic assumptions for regression analyses were satisfied. An alpha level of 0.05 was established throughout all analyses.

\footnotetext{
Notice: this is the author's version of a work that was accepted for publication in Research in Autism Spectrum Disorders. Changes resulting from the publishing process, such as peer review, editing, corrections, structural formatting, and other quality control mechanisms may not be reflected in this document. Changes may have been made to this work since it was submitted for publication. A definitive version was subsequently published in Research in Autism Spectrum Disorders, 8, 716-725, doi: 10.1016/j.rasd.2014.03.008.
} 


\section{Results}

\subsection{Child behavior problems}

Significantly more behavior problems, both externalizing and internalizing, were reported in the ASD group compared to the control group (Externalizing: $t_{(390)}=15.63, p<$ .001 ; Internalizing: $\left.t_{(389)}=20.65, p<.001\right)$. In the ASD group, a large amount of children had a clinically significant score on the SDQ subscales measuring externalizing problems and internalizing problems.

\section{[Table 2]}

\subsection{Behavior problems and their association with child characteristics and parenting}

\section{behaviors}

Pearson correlations (see Table 3) indicated that in the ASD group pragmatic language difficulties, positive parenting, and negative control were positively associated with externalizing problems. Pragmatic language difficulties and ASD adapted parenting were the only variables found to demonstrate significant positive associations with internalizing behavior problems. In the control group, significant small to moderate positive correlations were found between age, gender, structural language difficulties, pragmatic language difficulties, negative control, and externalizing behavior problems. Internalizing behavior problems were only significantly correlated with structural and pragmatic language difficulties and ASD adapted parenting.

\section{[Table 3]}

\footnotetext{
Notice: this is the author's version of a work that was accepted for publication in Research in Autism Spectrum Disorders. Changes resulting from the publishing process, such as peer review, editing, corrections, structural formatting, and other quality control mechanisms may not be reflected in this document. Changes may have been made to this work since it was submitted for publication. A definitive version was subsequently published in Research in Autism Spectrum Disorders, 8, 716-725, doi: 10.1016/j.rasd.2014.03.008.
} 


\subsubsection{Predictors of externalizing behavior problems}

Hierarchical multiple regression analyses were used to investigate the unique contribution of child age, gender, communication difficulties, and parenting behaviors to externalizing and internalizing behavior problems among children with and without ASD. Results of the regression analyses are shown in Tables 4 and 5. For the ASD group, adding age and gender into the regression model did not explain a significant variance in externalizing behavior problems. Pragmatic language difficulties at step 2 and negative control at step 3 showed a positive relationship with externalizing behavior problems. Together, these predictors explained $15 \%$ of the variance in externalizing behavior problems $\left(F_{(3,196)}=6.41 ; p<.001\right)$.

For the control group, age and gender accounted for a significant proportion of the variance in externalizing behavior problems. Together with pragmatic language difficulties, these variables explained $29 \%$ of the variance $\left(F_{(2,179)}=28.96 ; p<.001\right)$. Adding parenting behaviors into the regression model did not result in a significant change in the explained variance in externalizing behavior problems among children without ASD. However, also in this group negative control was related to externalizing behavior problems.

\subsubsection{Predictors of internalizing behavior problems}

For the ASD group, adding age and gender into the regression model did not explain a significant proportion of the variance in internalizing behavior problems. Pragmatic language difficulties at step 2 and ASD adapted parenting at step 3 showed a positive relationship with internalizing problems. These variables accounted for $18 \%$ of the variance $\left(F_{(3,196)}=2.91 ; p=\right.$

\footnotetext{
Notice: this is the author's version of a work that was accepted for publication in Research in Autism Spectrum Disorders. Changes resulting from the publishing process, such as peer review, editing, corrections, structural formatting, and other quality control mechanisms may not be reflected in this document. Changes may have been made to this work since it was submitted for publication. A definitive version was subsequently published in Research in Autism Spectrum Disorders, 8 , 
.036). Standardized coefficients showed that pragmatic language difficulties were the strongest predictor, followed by ASD adapted parenting.

Similar results were found for the control group. Age and gender did not account for a significant proportion of the variance in internalizing behavior problems. Only pragmatic language difficulties and ASD adapted parenting were significant predictors for internalizing problems. These variables accounted for $19 \%$ of the variance $\left(F_{(3,176)}=2.85 ; p=.039\right)$.

\subsubsection{Moderator effects}

In the fourth step of the hierarchical regression analyses, the interaction terms between communication difficulties and parenting behaviors were included, in order to examine possible moderator effects. These analyses revealed no significant results.

\section{[Table 4]}

\section{[Table 5]}

\section{Discussion}

Although a multitude of studies have identified various risk factors for the emergence and maintenance of behavior problems among children in the general population at the child, family and contextual level, in the autism field most studies have only focused on the role of child characteristics. The present study extends previous findings and contributes to our

\footnotetext{
Notice: this is the author's version of a work that was accepted for publication in Research in Autism Spectrum Disorders. Changes resulting from the publishing process, such as peer review, editing, corrections, structural formatting, and other quality control mechanisms may not be reflected in this document. Changes may have been made to this work since it was submitted for publication. A definitive version was subsequently published in Research in Autism Spectrum Disorders, 8, 
knowledge about possible predictors for behavior problems in ASD by focusing on the predictive value of both child and family characteristics.

The first goal of this study was to investigate the unique contribution of child age and gender, children's communication difficulties and parenting behaviors to externalizing and internalizing behavior problems among school-aged children with and without ASD. The current study indicated no age and gender effects for the ASD group. Regarding children's communication difficulties, only difficulties in pragmatic language were identified as a significant predictor for both externalizing and internalizing problems among children with ASD. Similar results were found for the control group, except for an age effect present in the control group, with externalizing problems being more often reported in younger children.

The results of the current study showed a positive association between pragmatic language difficulties and behavior problems. Structural language difficulties did not account for significant variance in behavior problems. This is in line with the findings from Park and colleagues (2012), who found no significant association between structural language skills and behavior problems for preschool children with ASD. The results of their study suggested that communication skills were more closely linked to functional and behavioral outcomes than structural language skills. Furthermore, for most children with ASD structural language difficulties become more subtle by school age, whereas difficulties with pragmatic language persist and may become more prominent (Boucher, 2012). Pragmatic language impairments, such as difficulties in initiating a conversation or in taking turns and developing a topic while having a conversation, can hinder children to communicate their thoughts and needs. As a consequence, children with pragmatic language difficulties can be at greater risk for using compensatory externalizing strategies as a means to achieve desired goals (Fagan \& Iglesias,

\footnotetext{
Notice: this is the author's version of a work that was accepted for publication in Research in Autism Spectrum Disorders. Changes resulting from the publishing process, such as peer review, editing, corrections, structural formatting, and other quality control mechanisms may not be reflected in this document. Changes may have been made to this work since it was submitted for publication. A definitive version was subsequently published in Research in Autism Spectrum Disorders, 8, 716-725, doi: 10.1016/j.rasd.2014.03.008.
} 
2000). Pragmatic language also plays an important role in children's relationships with peers, especially in the school age period. When children face difficulties in achieving social goals through language, this may make them feel more insecure about engaging in these situations (Coplan \& Weeks, 2009). These negative social experiences might contribute to heightened internalizing problems. This is in particular the case for cognitively able children, since they can be more aware of these difficulties (Mazurek \& Kanne, 2010).

Concerning the role of parenting behaviors, the results of this study suggest that different types of parenting behaviors are associated with externalizing and internalizing problems. Negative, controlling parenting behaviors, i.e. discipline and harsh punishment, made a significant and unique positive contribution to externalizing behavior problems for the ASD group, whereas ASD adapted parenting behaviors were positively associated with internalizing problems both for the ASD and control group. Although negative, controlling parenting behaviors were correlated with externalizing problems in the control group, this variable did not remain significant in the final regression model. The association between harsh or negative parental control strategies and externalizing problems has been extensively demonstrated in studies from the general population (e.g., Kawabata et al., 2011; Smith et al., 2004). An important theory in this respect is the social interactional theory of Patterson and colleagues (Patterson, Reid, \& Dishion, 1992), in which family management practices such as monitoring, discipline and positive reinforcement are emphasized. Patterson identified a pattern of coercive interactions, where aversive child behaviors reciprocally influence parenting behaviors, and in which negative reinforcement results in maintenance of undesirable behaviors in both child and parent (Patterson, 1982; Reid, Patterson, \& Snyder, 2002). The cross-sectional nature of this study makes it difficult to infer causal relations. In

\footnotetext{
Notice: this is the author's version of a work that was accepted for publication in Research in Autism Spectrum Disorders. Changes resulting from the publishing process, such as peer review, editing, corrections, structural formatting, and other quality control mechanisms may not be reflected in this document. Changes may have been made to this work since it was submitted for publication. A definitive version was subsequently published in Research in Autism Spectrum Disorders, 8, 
order to identify coercive family processes among families of children with ASD, longitudinal designs are urgently needed.

By contrast, internalizing problems were not related to general parenting behaviors, but to ASD-adapted parenting behaviors in the ASD and control group. As suggested by Maljaars, Boonen, Lambrechts, Van Leeuwen, and Noens (2013), this can be explained by the fact that the internalizing problem factor of the SDQ does not only concern emotional problems, but also social problems with peers. Given that the latter are part of the diagnostic criteria for ASD (American Psychiatric Association, 2013), it is not surprising that a rise in ASD-adapted parenting went together with increasing internalizing problems.

However, the direction of the relationship between parenting behaviors and children's behavior problems is not apparent from the analyses and almost all of the significant effects were rather small. This can be due to the measures used in this study. The SDQ is a very short screening questionnaire and does not identify all areas of additional difficulties among children with ASD. For this reason the measure is possibly not sensitive enough to differentiate in degree of behavior problems within the ASD and the control group. Furthermore, ratings on parenting behaviors could be influenced by socially desirable responding, because of the use of self-report measures (Maljaars et al., 2013).

The second purpose of this study was to investigate possible moderator effects between child communication difficulties and parenting behaviors in predicting children's behavior problems. The current study did not reveal significant moderator effects between the child and family variables. In this study, parenting behavior seems to act as an additional factor, next to communication problems, that contributes to the prediction of behavior problems. This finding stresses the importance of incorporating family characteristics, next to child

\footnotetext{
Notice: this is the author's version of a work that was accepted for publication in Research in Autism Spectrum Disorders. Changes resulting from the publishing process, such as peer review, editing, corrections, structural formatting, and other quality control mechanisms may not be reflected in this document. Changes may have been made to this work since it was submitted for publication. A definitive version was subsequently published in Research in Autism Spectrum Disorders, 8, 716-725, doi: 10.1016/j.rasd.2014.03.008.
} 
characteristics, when investigating predictors for behavior problems among children with ASD.

A first and important limitation of the current study is its cross-sectional design. Given the concurrent assessment of predictor and outcome variables, it is impossible to formulate conclusions about directionality. Within a developmental psychopathology framework, it is supposed that there are multiple possible pathways in the development of behavior problems, and that multiple risk and protective factors can influence these pathways. In order to get a deeper understanding of these pathways among children with ASD and possible factors which enhance or decrease risk for developing behavior problems, longitudinal designs are needed. A second limitation is that other important predictors for children's behavior problems were not investigated in this study, such as parenting stress (Hastings, 2002; Bauminger, Solomon, \& Rogers, 2010), several other child factors, such as child temperament (De Pauw, Mervielde, Van Leeuwen, \& De Clercq, 2011) and severity of ASD symptoms, or contextual factors (Kanne \& Mazurek, 2011; Midouhas et al., 2013). Future research needs to take these variables into consideration when investigating the role of both child and family characteristics in the development of behavior problems among children with ASD. A third limitation is that we only used parent report measures, potentially leading to some type of reporter bias. Future research would benefit from the use of multiple informant sources. Furthermore, direct observations would be useful in order to obtain a more independent assessment of parenting behaviors and child behavior problems. A final limitation of the current study is a possible sample selection bias, since a large amount of the participants were recruited via ASD parent associations.

\footnotetext{
Notice: this is the author's version of a work that was accepted for publication in Research in Autism Spectrum Disorders. Changes resulting from the publishing process, such as peer review, editing, corrections, structural formatting, and other quality control mechanisms may not be reflected in this document. Changes may have been made to this work since it was submitted for publication. A definitive version was subsequently published in Research in Autism Spectrum Disorders, 8, 716-725, doi: 10.1016/j.rasd.2014.03.008.
} 
Despite these limitations, the study fills an important gap in the literature, as it is one of the first to incorporate child and family characteristics while investigating predictors for behavior problems among school-aged children with ASD. The results suggest that children's communication difficulties and parenting behaviors contribute uniquely to externalizing and internalizing problems. Prevention and intervention programs for children with ASD and additional behavior problems would benefit from targeting not only the child's behavior and communication skills, but also parenting skills. Helping parents to enhance their parenting skills may promote their successful management of their child's behavior problems.

\section{Acknowledgements}

This research was funded by the Marguerite-Marie Delacroix Support Fund and the Research Fund Katholieke Universiteit Leuven. Furthermore, we thank all the participating families and schools, as well as the Dutch parent association for ASD.

\section{References}

American Psychiatric Association (2013). Diagnostic and statistical manual of mental disorders (5th ed.). Washington, DC: APA.

Barber, B. K., Stolz, H. E., \& Olsen J. A. (2005). Parental support, psychological control, and behavioral control: Assessing relevance across time, culture, and method. Monographs of the Society for Research in Child Development, 70, 1-137.

Bauminger, N., Solomon, M., \& Rogers, S. J. (2010). Externalizing and internalizing behaviors in ASD. Autism Research, 3, 101-112.

Bishop, D. V. M. (2003). The Children's Communication Checklist-2. London: Psychological Corporation.

Boucher, J. (2012). Research review: Structural language in autistic spectrum disorder - characteristics and causes. Journal of Child Psychology and Psychiatry, 53, 219-233.

Calkins, S. D. (1994). Origins and outcomes of individual differences in emotion regulation. Monographs for the Society for Research on Child Development, 59(2-3,Serial No. 240), 53-72.

Notice: this is the author's version of a work that was accepted for publication in Research in Autism Spectrum Disorders. Changes resulting from the publishing process, such as peer review, editing, corrections, structural formatting, and other quality control mechanisms may not be reflected in this document. Changes may have been made to this work since it was submitted for publication. A definitive version was subsequently published in Research in Autism Spectrum Disorders, 8,

716-725, doi: 10.1016/j.rasd.2014.03.008. 
Calkins, S. D., Blandon, A. Y., Williford, A. P., \& Keane, S. P. (2007). Biological, behavioral, and relational levels of resilience in the context of risk for early childhood behavior problems. Development and Psychopathology, 19, 675-700.

Calkins, S. D., \& Fox, N. A. (2002). Self-regulatory processes in early personality development: A multilevel approach to the study of childhood social withdrawal and aggression. Development and Psychopathology, 14, 477-498.

Caron, A., Weiss, B., Harris, V., \& Catron, T. (2006). Parenting behavior dimensions and child psychopathology: Specificity, task dependency, and interactive relations. Journal of Clinical Child and Adolescent Psychology, 35, 34-45.

Carter, A. S., Martínez-Pedraza, F. de L., \& Gray, S. A. O. (2009). Stability and individual change in depressive symptoms among mothers raising young children with ASD: Maternal and child correlates. Journal of Clinical Psychology, 65, 1270-1280.

Coplan, R. J., \& Weeks, M. (2009). Shy and soft-spoken: Shyness, pragmatic language, and socio-emotional adjustment in early childhood. Infant and Child Development, 18, 238-254.

De Pauw, S. S. W., Mervielde, I., Van Leeuwen, K. G., \& De Clercq, B. J. (2011). How temperament and personality contribute to the maladjustment of children with autism. Journal of Autism and Developmental Disorders, 41, 196-212.

Dionne, G., Tremblay, R., Boivin, M., Laplante, D., \& Pérusse, D. (2003). Physical aggression and expressive vocabulary in 19-month-old twins. Developmental Psychology, 39, 261-273.

Dominick, K. C., Davis, N. O., Lainhart, J., Tager-Flusberg, H., \& Folstein, S. (2007). Atypical behaviors in children with autism and children with a history of language impairment. Research in Developmental Disabilities, 28, 145-162.

Estes, A., Olson, E., Sullivan, K., Greenson, J., Winter, J., Dawson, G., \& Munson, J. (2013). Parenting-related stress and psychological distress in mothers of toddlers with autism spectrum disorders. Brain \& Development, 35, 133-138.

Fagan, J., \& Iglesias, A. (2000). The relationship between fathers' and children's communication skills and children's behavior problems: A study of Head Start Children. Early Education and Development, 11, 307320 .

Field, A. (2009). Discovering statistics using SPSS ( $3^{\text {rd }}$ ed.). London: Sage.

Finkenauer, C., Engels, R., \& Baumeister, R. (2005). Parenting behavior and adolescent behavioral and emotional problems: The role of self-control. International Journal of Behavioral Development, 29, 58-69.

Gavidia-Payne, S., \& Hudson, A. (2002). Behavioural supports for parents of children with an intellectual disability and problem behaviours: An overview of the literature. Journal of Intellectual and Developmental Disability, 27, 31-55.

Geurts, H. M. (2007). CCC-2-NL: Children's Communication Checklist-2. Amsterdam: Harcourt Assessment BV.

Goodman, R. (1997). The Strengths and Difficulties Questionnaire: A research note. Journal of Child Psychology and Psychiatry, 38, 581-586.

Goodman, R. (2001). Psychometric properties of the Strengths and Difficulties Questionnaire. Journal of the American Academy of Child and Adolescent Psychiatry, 40, 1337-1345.

Notice: this is the author's version of a work that was accepted for publication in Research in Autism Spectrum Disorders. Changes resulting from the publishing process, such as peer review, editing, corrections, structural formatting, and other quality control mechanisms may not be reflected in this document. Changes may have been made to this work since it was submitted for publication. A definitive version was subsequently published in Research in Autism Spectrum Disorders, 8,

716-725, doi: 10.1016/j.rasd.2014.03.008. 
Goodman, A., \& Goodman, R. (2009). Strengths and Difficulties Questionnaire as a dimensional measure of child mental health. Journal of the American Academy of Child and Adolescent Psychiatry, 48, 400-403.

Goodman, A., Lamping, D. L., \& Ploubidis, G. B. (2010). When to use broader internalising and externalising subscales instead of the hypothesised five subscales on the Strengths and Difficulties Questionnaire (SDQ): Data from British parents, teachers and children. Journal of Abnormal Child Psychology, 38, 1179-1191.

Gray, K., Keating, C., Taffe, J., \& Brereton, A. (2012). Trajectory of behavior and emotional problems in autism. American Journal on Intellectual and Developmental Disabilities, 117, 121-133.

Hartas, D. (2011). The ecology of young children's behaviour and social competence: Child characteristics, socio-economic factors and parenting. Oxford Review of Education, 37, 763-783.

Hastings, R. P. (2002). Parental stress and behaviour problems of children with developmental disability. Journal of Intellectual and Developmental Disability, 27, 149-160.

Hastings, R., Kovshoff, H., Ward, N., Espinosa, F., Brown, T., \& Remington, B. (2005). Systems analysis of stress and positive perceptions in mothers and fathers of pre-school children with autism. Journal of Autism and Developmental Disorders, 35, 635-644.

Hartley, S. L., Sikora, D. M., \& McCoy, R. (2008). Prevalence and risk factors of maladaptive behaviour in young children with autistic disorder. Journal of Intellectual Disability Research, 52, 819-829.

Herring, S., Gray, K., Taffe, J., Tonge, B., Sweeney, D., \& Einfeld, S. (2006). Behaviour and emotional problems in toddlers with pervasive developmental disorders and developmental delay: Associations with parental mental health and family functioning. Journal of Intellectual Disability Research, 50, 874-882.

Kanne, S. M., \& Mazurek, M. O. (2011). Aggression in children and adolescents with ASD: Prevalence and risk factors. Journal of Autism and Developmental Disorders, 41, 926-937.

Kawabata, Y., Alink, L. R. A., Tseng, W.-L., Van IJzendoorn, M. H., \& Crick, N. R. (2011). Maternal and paternal parenting styles associated with relational aggression in children and adolescents: A conceptual analysis and meta-analytic review. Developmental Review, 31, 240-278.

Lahey, B. B., Schwab-Stone, M., Goodman, S. H., Waldman, I. D., Canino, G., Rathouz, P. J., Miller, T. L., Dennis, K. D., Bird, H., \& Jensen, P. S. (2000). Age and gender differences in oppositional behavior and conduct problems: A cross-sectional household study of middle childhood and adolescence. Journal of Abnormal Psychology, 109, 488-503.

Lambrechts, G., Van Leeuwen, K., Boonen, H., Maes, B., \& Noens, I. (2011). Parenting behavior among parents of children with autism spectrum disorder [corrected]. Research in Autism Spectrum Disorders, 5, 11431152 .

Lecavalier, L., Leone, S., \& Wiltz, J. (2006). The impact of behavior problems on caregiver stress in young people with autism spectrum disorders. Journal of Intellectual Disability Research, 50, 172-183.

Maljaars, J., Boonen, H., Lambrechts, G., Van Leeuwen, K., \& Noens, I. (2014). Maternal parenting behavior and child behavior problems in families of children and adolescents with autism spectrum disorder. Journal of Autism and Developmental Disorders, 44, 501-512.

Matson, J. L., Mahan, S., Hess, J. A., Fodstad, J. C., \& Neal, D. (2010). Progression of challenging behaviors in children and adolescents with autism spectrum disorders as measured by the Autism Spectrum DisordersProblem Behaviors for Children (ASD-PBC). Research in Autism Spectrum Disorders, 4, 400-404.

Notice: this is the author's version of a work that was accepted for publication in Research in Autism Spectrum Disorders. Changes resulting from the publishing process, such as peer review, editing, corrections, structural formatting, and other quality control mechanisms may not be reflected in this document. Changes may have been made to this work since it was submitted for publication. A definitive version was subsequently published in Research in Autism Spectrum Disorders, 8, 716-725, doi: 10.1016/j.rasd.2014.03.008. 
Matson, J. L., \& Wilkins, J. (2007). A critical review of assessment targets and methods for social skills excesses and deficits for children with autism spectrum disorders. Research in Autism Spectrum Disorders, 1, 28-37.

Mazurek, M. O., \& Kanne, S. M. (2010). Friendship and internalizing symptoms among children and adolescents with ASD. Journal of Autism and Developmental Disorders, 40, 1512-1520.

McStay, R. L., Dissanayake, C., Scheeren, A., Koot, H. M., \& Begeer, S. (2013). Parenting stress and autism: The role of age, autism severity, quality of life and problem behaviour of children and adolescents with autism. Autism. doi:10.1177/1362361313485163

McTiernan, A., Leader, G., Healy, O., \& Mannion, A. (2011). Analysis of risk factors and early predictors of challenging behavior for children with autism spectrum disorder. Research in Autism Spectrum Disorders, 5, $1215-1222$.

Midouhas, E., Yogaratnam, A., Flouri, E., \& Charman, T. (2013). Psychopathology Trajectories of Children With Autism Spectrum Disorder: The Role of Family Poverty and Parenting. Journal of the American Academy of Child \& Adolescent Psychiatry, 52, 1057-1065.e1

Muris, P., Meesters, C., \& Van den Berg, F. (2003). The Strengths and Difficulties Questionnaire (SDQ): Further evidence for its reliability and validity in a community sample of Dutch children and adolescents. European Child and Adolescent Psychiatry, 12, 1-8.

Osborne, L. A., McHugh, L., Saunders, J., \& Reed, P. (2008). The effect of parenting behaviors on subsequent child behavior problems in autistic spectrum conditions. Research in Autism Spectrum Disorders, 2, 249263.

Park, C. J., Yelland, G. W., Taffe, J. R., \& Gray, K. M. (2012). Brief report: The relationship between language skills, adaptive behavior, and emotional and behavior problems in pre-schoolers with autism. Journal of Autism and Developmental Disorders, 42, 2761-2766.

Patterson, G. R. (1982). Coercive family process: A social interactional approach (Volume 3). Eugene, OR: Castalia Publishing Company.

Patterson, G. R., Reid, J., \& Dishion, T. (1992). Antisocial boys. A social interactional approach (Volume 4). Eugene, OR: Castalia Publishing Company.

Pettit, G. S., Bates, J. E., \& Dodge, K. E. (1993). Family interaction patterns and children's conduct problems at home and school: A longitudinal perspective. School Psychology Review, 22, 403-420.

Reid, J. B., Patterson, G. R., \& Snyder, J. J. (Eds.) (2002). Antisocial behavior in children and adolescents: A developmental analysis and model for intervention. Washington, DC: American Psychological Association.

Repp, A., \& Horner, R. H. (Eds.). (1999). Functional analysis of problem behavior: From effective assessment to effective support. Belmont, CA: Wadsworth.

Sikora, D., Moran, E., Orlich, F., Hall, T. A., Kovacs, E. A., Delahaye, J., Clemons, T. E., \& Kuhlthau, K. (2013). The relationship between family functioning and behavior problems in children with autism spectrum disorders. Research in Autism Spectrum Disorders, 7, 307-315.

Smith, C. L., Calkins, S. D., Keane, S. P., Anastopoulos, A. D., \& Shelton, T. L. (2004). Predicting stability and change in toddler behavior problems: Contributions of maternal behavior and child gender. Developmental Psychology, 40, 29-42.

Notice: this is the author's version of a work that was accepted for publication in Research in Autism Spectrum Disorders. Changes resulting from the publishing process, such as peer review, editing, corrections, structural formatting, and other quality control mechanisms may not be reflected in this document. Changes may have been made to this work since it was submitted for publication. A definitive version was subsequently published in Research in Autism Spectrum Disorders, 8, 
Taylor, J. L., \& Seltzer, M. M. (2011). Employment and post-secondary educational activities for young adults with autism spectrum disorders during transition to adulthood. Journal of Autism and Developmental Disorders, 41, 566-574.

Tomanik, S., Harris, G. E., \& Hawkins, J. (2004). The relationship between behaviors exhibited by children with autism and maternal stress. Journal of Intellectual and Developmental Disability, 29, 16-26.

Tremblay, R. E. (2000). The development of aggressive behaviour during childhood: What have we learned in the past century? International Journal of Behavioral Development, 24, 129-141.

Van Leeuwen, K. \& Noens, I. (2013). Parental Behavior Scale for Autism spectrum disorders. Unpublished document, Leuven: KU Leuven.

Van Leeuwen K. G., \& Vermulst, A. A. (2004). Some psychometric properties of the Ghent Parental Behavior Scale. European Journal of Psychological Assessment, 20, 283-298.

Van Leeuwen, K., \& Vermulst, A. (2010). Handleiding bij de Verkorte Schaal voor Ouderlijk Gedrag [Manual of the Short Version of the Parental Behavior Scale]. Unpublished document, Leuven: Katholieke Universiteit Leuven.

Wood, J. J., McLeod, B. D., Sigman, M., Hwang, W. C., \& Chu, B. C. (2003). Parenting and childhood anxiety: Theory, empirical findings, and future directions. Journal of Child Psychology and Psychiatry and Allied Disciplines, 44, 134-151.

Notice: this is the author's version of a work that was accepted for publication in Research in Autism Spectrum Disorders. Changes resulting from the publishing process, such as peer review, editing, corrections, structural formatting, and other quality control mechanisms may not be reflected in this document. Changes may have been made to this work since it was submitted for publication. A definitive version was subsequently published in Research in Autism Spectrum Disorders, 8, 
Table 1.

Demographic Characteristics of the ASD and Control Group

\begin{tabular}{|c|c|c|c|c|c|}
\hline & & $\begin{array}{l}\text { Control } \\
(n=187)\end{array}$ & $\begin{array}{l}\text { ASD } \\
(n=206)\end{array}$ & Test statistic & $p$ \\
\hline \multicolumn{6}{|l|}{ Child characteristics } \\
\hline \multirow[t]{2}{*}{ Age } & Range & $6-12$ & $6-12$ & $t_{(391)}=-4.18$ & $<.001$ \\
\hline & $M(\mathrm{SD})$ & $9.2(1.9)$ & $9.9(1.8)$ & & \\
\hline \multirow[t]{2}{*}{ Gender } & Boys & $47 \%$ & $85 \%$ & $X_{(1)}^{2}=67.05$ & $<.001$ \\
\hline & Girls & $53 \%$ & $15 \%$ & & \\
\hline \multicolumn{6}{|l|}{ Parent characteristics } \\
\hline \multirow[t]{2}{*}{ Age mothers } & Range & $29-55$ & $31-52$ & $t_{(363)}=-.13$ & .90 \\
\hline & $M(\mathrm{SD})$ & $41.4(4.8)$ & $41.5(4)$ & & \\
\hline \multirow[t]{2}{*}{ Age fathers } & Range & $32-58$ & $31-73$ & $t_{(379)}=-1.56$ & .12 \\
\hline & $M(\mathrm{SD})$ & $43.7(5.1)$ & $44.5(5.1)$ & & \\
\hline \multirow[t]{2}{*}{ Education level mothers } & No college & $55 \%$ & $56 \%$ & $X_{(1)}^{2}=0.02$ & .90 \\
\hline & College completed & $45 \%$ & $44 \%$ & & \\
\hline \multirow[t]{2}{*}{ Education level fathers } & No college & $44 \%$ & $51 \%$ & $X_{(1)}^{2}=1.91$ & .17 \\
\hline & College completed & $56 \%$ & $49 \%$ & & \\
\hline \multicolumn{6}{|l|}{ Family characteristics } \\
\hline \multirow[t]{2}{*}{$N$ of children } & Range & $1-5$ & $1-13$ & $t_{(387)}=-.59$ & .56 \\
\hline & $M(\mathrm{SD})$ & $2.3(0.7)$ & $2.3(1.1)$ & & \\
\hline \multirow[t]{2}{*}{ Marital status } & Single-parent & $8 \%$ & $12 \%$ & $X^{2}{ }_{(1)}=1.79$ & .18 \\
\hline & Two parents & $92 \%$ & $88 \%$ & & \\
\hline
\end{tabular}

Notice: this is the author's version of a work that was accepted for publication in Research in Autism Spectrum Disorders. Changes resulting from the publishing process, such as peer review, editing, corrections, structural formatting, and other quality control mechanisms may not be reflected in this document. Changes may have been made to this work since it was submitted for publication. A definitive version was subsequently published in Research in Autism Spectrum Disorders, 8, 


\section{Table 2.}

Percentages of Clinically Significant Scores on the SDQ for the ASD Group and Control Group

\begin{tabular}{llll}
\hline Behavior problems & & $\begin{array}{l}\text { ASD group } \\
(n=206)\end{array}$ & $\begin{array}{l}\text { Control group } \\
(n=187)\end{array}$ \\
\hline Externalizing & Conduct problems & $28.2 \%$ & $2.7 \%$ \\
& Hyperactivity/inattention & $53.4 \%$ & $11.8 \%$ \\
Internalizing & Emotional symptoms & $57.8 \%$ & $12.3 \%$ \\
& Peer relationship problems & $70.9 \%$ & $8.6 \%$ \\
\hline
\end{tabular}

Notice: this is the author's version of a work that was accepted for publication in Research in Autism Spectrum Disorders. Changes resulting from the publishing process, such as peer review, editing, corrections, structural formatting, and other quality control mechanisms may not be reflected in this document. Changes may have been made to this work since it was submitted for publication. A definitive version was subsequently published in Research in Autism Spectrum Disorders, 8, 
Table 3 .

Pearson correlations between Child Behavior Problems, Child Characteristics, and Parenting

Behaviors for the ASD Group (upper side) and the Control Group (lower side)

\begin{tabular}{|c|c|c|c|c|c|c|c|c|c|}
\hline & 1 & 2 & 3 & 4 & 5 & 6 & 7 & 8 & 9 \\
\hline 1. Externalizing behavior problems & & $.17^{*}$ & -.00 & -.02 & .10 & $.24 * *$ & $.16^{*}$ & $.28 * *$ & .10 \\
\hline 2. Internalizing behavior problems & $.39 * *$ & & .00 & .09 & .13 & $.36 * *$ & .06 & .01 & $.27 * *$ \\
\hline 3. Age of the child & $-.15^{*}$ & .05 & & .01 & .01 & -.01 & -.08 & -0.2 & -.08 \\
\hline 4. Gender of the child & $-.16^{*}$ & -.10 & -.01 & & .14 & .06 & -.04 & $-.23 * *$ & $.17 *$ \\
\hline 5. Structural language difficulties & $.33 * *$ & $.24 * *$ & $.15^{*}$ & -.08 & & $.57 * *$ & .09 & $-.15^{*}$ & $.24 * *$ \\
\hline 6. Pragmatic language difficulties & $.49 * *$ & $.38 * *$ & .05 & -.14 & $.66^{* *}$ & & .03 & -.03 & $.28 * *$ \\
\hline 7. Positive parenting & .04 & .10 & $-.18^{*}$ & -.03 & -.00 & -.01 & & $.24 * *$ & $.42 * *$ \\
\hline 8. Negative control & $.21 * *$ & .09 & $-.20 * *$ & -.04 & -.02 & .06 & $.29 * *$ & & -.01 \\
\hline 9. ASD adapted parenting & -.01 & $.21 * *$ & -.08 & -.03 & -.02 & .03 & $.60 * *$ & .12 & \\
\hline
\end{tabular}

$* p<.05 ; * * p<.01$

Notice: this is the author's version of a work that was accepted for publication in Research in Autism Spectrum Disorders. Changes resulting from the publishing process, such as peer review, editing, corrections, structural formatting, and other quality control mechanisms may not be reflected in this document. Changes may have been made to this work since it was submitted for publication. A definitive version was subsequently published in Research in Autism Spectrum Disorders, 8, 
Table 4.

Hierarchical Regression Analyses for Externalizing Behavior Problems for the ASD group $(n=204)$ and the Control Group $(n=184)$

\begin{tabular}{|c|c|c|c|c|c|c|c|}
\hline Group & Step & Predictor & Beta & $t$ & $p$ & $R^{2}$ & $p \Delta R^{2}$ \\
\hline \multirow[t]{13}{*}{$\overline{\text { ASD }}$} & \multirow[t]{2}{*}{1} & Age & .00 & 0.03 & .980 & \multirow[t]{2}{*}{.00} & \multirow[t]{2}{*}{.96} \\
\hline & & Gender & -.02 & -0.28 & .777 & & \\
\hline & \multirow[t]{4}{*}{2} & Age & .00 & 0.05 & .961 & \multirow[t]{4}{*}{.06} & \multirow[t]{4}{*}{.002} \\
\hline & & Gender & -.03 & -0.42 & 674 & & \\
\hline & & Structural Language Difficulties & -.05 & -0.64 & .522 & & \\
\hline & & Pragmatic Language Difficulties & .27 & 3.26 & .001 & & \\
\hline & \multirow[t]{7}{*}{3} & Age & .01 & 0.20 & .838 & \multirow[t]{7}{*}{.15} & \multirow[t]{7}{*}{$<.001$} \\
\hline & & Gender & .03 & 0.44 & .659 & & \\
\hline & & Structural Language Difficulties & -.02 & -0.28 & .778 & & \\
\hline & & Pragmatic Language Difficulties & .26 & 3.15 & .002 & & \\
\hline & & Positive Parenting & .09 & 1.19 & .235 & & \\
\hline & & Negative Control & .26 & 3.72 & $<.001$ & & \\
\hline & & ASD Adapted parenting & -.01 & -0.08 & 941 & & \\
\hline \multirow{13}{*}{ Control } & \multirow[t]{2}{*}{1} & Age & -.15 & -2.09 & .038 & \multirow[t]{2}{*}{.05} & \multirow[t]{2}{*}{.007} \\
\hline & & Gender & -.18 & -2.44 & .016 & & \\
\hline & \multirow[t]{4}{*}{2} & Age & -.19 & -2.89 & .004 & \multirow[t]{4}{*}{.29} & \multirow[t]{4}{*}{$<.001$} \\
\hline & & Gender & -.11 & -1.71 & .089 & & \\
\hline & & Structural Language Difficulties & .09 & 1.06 & .290 & & \\
\hline & & Pragmatic Language Difficulties & .42 & 4.95 & $<.001$ & & \\
\hline & \multirow[t]{7}{*}{3} & Age & -.16 & -2.42 & .016 & \multirow[t]{7}{*}{.31} & \multirow[t]{7}{*}{.075} \\
\hline & & Gender & -.11 & -1.68 & .094 & & \\
\hline & & Structural Language Difficulties & .10 & 1.16 & 248 & & \\
\hline & & Pragmatic Language Difficulties & .40 & 4.80 & $<.001$ & & \\
\hline & & Positive Parenting & .00 & 0.03 & .976 & & \\
\hline & & Negative Control & .16 & 2.47 & .014 & & \\
\hline & & ASD Adapted parenting & -.06 & -0.79 & .429 & & \\
\hline
\end{tabular}

Notice: this is the author's version of a work that was accepted for publication in Research in Autism Spectrum Disorders. Changes resulting from the publishing process, such as peer review, editing, corrections, structural formatting, and other quality control mechanisms may not be reflected in this document. Changes may have been made to this work since it was submitted for publication. A definitive version was subsequently published in Research in Autism Spectrum Disorders, 8, 
Table 5 .

Hierarchical Regression Analyses for Internalizing Behavior Problems for the ASD group $(n=204)$ and the Control Group $(n=184)$

\begin{tabular}{|c|c|c|c|c|c|c|c|}
\hline Group & Step & Predictor & Beta & $t$ & $p$ & $R^{2}$ & $p \Delta R^{2}$ \\
\hline \multirow[t]{13}{*}{$\overline{\text { ASD }}$} & \multirow[t]{2}{*}{1} & Age & .01 & 0.11 & .909 & \multirow[t]{2}{*}{.01} & \multirow[t]{2}{*}{.45} \\
\hline & & Gender & .09 & 1.26 & .208 & & \\
\hline & \multirow[t]{4}{*}{2} & Age & .01 & 0.16 & .870 & \multirow[t]{4}{*}{.14} & \multirow[t]{4}{*}{$<.001$} \\
\hline & & Gender & .08 & 1.19 & .235 & & \\
\hline & & Structural Language Difficulties & -.12 & -1.44 & .152 & & \\
\hline & & Pragmatic Language Difficulties & .42 & 5.27 & $<.001$ & & \\
\hline & \multirow[t]{7}{*}{3} & Age & .03 & 0.41 & 679 & \multirow[t]{7}{*}{.18} & \multirow[t]{7}{*}{.04} \\
\hline & & Gender & .05 & 0.77 & .438 & & \\
\hline & & Structural Language Difficulties & -.13 & -1.59 & .114 & & \\
\hline & & Pragmatic Language Difficulties & .37 & 4.58 & $<.001$ & & \\
\hline & & Positive Parenting & -.03 & -0.40 & .687 & & \\
\hline & & Negative Control & .03 & 0.46 & .648 & & \\
\hline & & ASD Adapted parenting & .21 & 2.77 & .006 & & \\
\hline \multirow[t]{12}{*}{ Control } & \multirow[t]{2}{*}{1} & Age & .06 & 0.76 & .446 & \multirow[t]{2}{*}{.01} & \multirow[t]{2}{*}{.27} \\
\hline & & Gender & -.11 & -1.42 & .158 & & \\
\hline & \multirow[t]{4}{*}{2} & Age & .04 & 0.60 & .546 & \multirow[t]{4}{*}{.15} & \multirow[t]{4}{*}{$<.001$} \\
\hline & & Gender & -.05 & -0.73 & .469 & & \\
\hline & & Structural Language Difficulties & -.03 & -0.35 & .727 & & \\
\hline & & Pragmatic Language Difficulties & .40 & 4.27 & $<.001$ & & \\
\hline & \multirow[t]{6}{*}{3} & Age & .06 & 0.86 & .391 & \multirow[t]{6}{*}{.19} & \multirow[t]{6}{*}{.039} \\
\hline & & Gender & -.44 & -0.65 & .519 & & \\
\hline & & Structural Language Difficulties & -.02 & -0.18 & .854 & & \\
\hline & & Pragmatic Language Difficulties & .38 & 4.08 & $<.001$ & & \\
\hline & & Positive Parenting & -.04 & -0.40 & 690 & & \\
\hline & & Negative Control & .05 & 0.74 & .461 & & \\
\hline
\end{tabular}

Notice: this is the author's version of a work that was accepted for publication in Research in Autism Spectrum Disorders. Changes resulting from the publishing process, such as peer review, editing, corrections, structural formatting, and other quality control mechanisms may not be reflected in this document. Changes may have been made to this work since it was submitted for publication. A definitive version was subsequently published in Research in Autism Spectrum Disorders, 8, 
Notice: this is the author's version of a work that was accepted for publication in Research in Autism Spectrum Disorders. Changes resulting from the publishing process, such as peer review, editing, corrections, structural formatting, and other quality control mechanisms may not be reflected in this document. Changes may have been made to this work since it was submitted for publication. A definitive version was subsequently published in Research in Autism Spectrum Disorders, 8, 